Atıf İçin: Kara N, 2021. Solucan Gübresinin Satureja hortensis L.'nin Herba Verimi ve Uçucu Yağ Oranına Etkisi. Iğdır Üniversitesi Fen Bilimleri Enstitüsü Dergisi, 11(2): 1635-1642.

To cite: Kara N, 2021. Effect of Vermicompost on Herb Yield and Essential Oil Content of Satureja hortensis. Journal of the Institute of Science and Technology, 11(2): 1635-1642.

\title{
Solucan Gübresinin Satureja hortensis L.'nin Herba Verimi ve Uçucu Yağ Oranına Etkisi
}

\section{Nimet KARA ${ }^{1 *}$}

ÖZET: Araştırma, Isparta koşullarında Satureja hortensis L.'nin herba verimi ve uçucu yağ oranına sıvı solucan gübresi uygulamasının etkisini araştırmak amacıyla 2019 ve 2020 yıllarında yürütülmüştür. Deneme, tesadüf blokları deneme desenine göre üç tekerrürlü olarak, geleneksel üretim (kontrol-G.Ü), yalın solucan gübresi (S.G) ve G.Ü+S.G'nin birlikte uygulanması şeklinde kurulmuştur. Satureja hortensis'in yaş herba uçucu yağ oranı dışında birinci ve ikinci biçimleri arasındaki farklar istatistiksel olarak önemli çıkmış ve birinci biçim ortalamaları önemli oranda daha yüksek olmuştur. Yalın solucan gübresi uygulamasından elde edilen bitki boyu, yaş herba, drog herba ve drog yaprak verimi ile uçucu yağ oranı, geleneksel üretim ve G.Ü+S.G'nin birlikte uygulanmasına göre daha düşük olmuştur. İncelenen karakterlerin en yüksek değerleri G.Ü+S.G'nin birlikte uygulanmasında belirlenmiştir. Geleneksel üretim+solucan gübresinin birlikte uygulamasından elde edilen drog yaprak verimi yalın solucan gübresine göre birinci yıl \%62.8, ikinci y1l \%35.7 ve geleneksel üretimden ise birinci yıl \%30.4, ikinci yı1 \%21.5 oranında daha fazla olmuştur. Sonuç olarak, üretici tercihine göre, organik ürün yetiştirmek amacıyla yalın sıvı solucan gübresi uygulanabilir olduğu, ancak daha yüksek yaş/drog herba ve drog yaprak veriminden dolayı solucan gübresinin geleneksel üretim ile birlikte uygulanması önerilmektedir.

Anahtar Kelimeler: Satureja, solucan gübresi, drog verimi, uçucu yağ oranı

\section{Effect of Vermicompost on Herb Yield and Essential Oil Content of Satureja hortensis}

\begin{abstract}
The research was carried out to investigate the effect of liquid vermicompost treatment on herb yield and essential oil content of Satureja hortensis' in Isparta conditions in 2019 and 2020 years. The experiment was set up in three replications according to the randomized complete block design by applying conventional production (C.P), alone vermicompost (V) and C.P+V together. The differences between the first and second harvests of Satureja hortensis, except for the essential oil content of fresh herb, were statistically significant, and the means of the first harvest were significantly higher. The plant height, fresh herb, dried herb, drug leaf yield and essential oil content values obtained from the application of alone vermicompost were lower than conventional production and the application of C.P+V together. The highest values of the examined characteristics were determined in the combination of C.P+V. The drug leaf yield obtained from the combined treatment of conventional production + vermicompost was $62.8 \%$ higher in the first year, $35.7 \%$ in the second year according to vermicompost fertilizer, and $30.4 \%$ in the first year and $21.5 \%$ in the second year compared to the conventional production. As a result, according to the producer preferer, alone liquid vermicompost should be applied with aim to grow organic crops, but combination of C.P+V is recommended due to higher fresh/dried herb and drug leaf yield.
\end{abstract}

Keywords: Satureja, vermicompost, drug yield, essential oil content

${ }^{1}$ Nimet KARA (Orcid ID: 0000-0001-7069-0877), Isparta Uygulamalı Bilimler Üniversitesi, Ziraat Fakültesi, Tarla Bitkileri Bölümü, Isparta, Türkiye

*Sorumlu yazar / Corresponding author: Nimet KARA e-mail: nimetkara@isparta.edu.tr 


\section{GÍRIȘ}

Dünyada tıbbi ve aromatik bitkilerin gıda, ilaç ve kozmetik sanayi gibi birçok alanda kullanımı ve tüketimi hızla artmaktadır. Anadolu'da kekik adıyla bilinen; Origanum, Thymus, Satureja, Coridothymus ve Thymbra cinslerinin bazı türleri doğadan toplanırken, bazılarının ise tarımı yapılmaktadır. Türkiye'de ticareti yapılan sater bitkisine ait önemli kekik türleri S. cuneifolia, S. thymbra, S. hortensis ve S. spicigera'dır (Satıl ve ark., 2008). Sater (Satureja hortensis L.) Türkiye'nin Karadeniz (Samsun), Akdeniz (Hatay), Doğu Anadolu (Erzurum ve Diyarbakır) ve Güney Doğu Anadolu (Kahramanmaraş) bölgeleri başta olmak üzere birçok yerinde doğal yayılış göstermektedir (Çoban, 2019). Satureja'nın büyük bir kısmı doğadan temin edilmekle birlikte Edirne, Balıkesir, Bursa, İzmir, Denizli, Konya, Eskişehir ve Kayseri illerinde kültürü yapılmaktadır (Aşçı, 2009).

Satureja hortensis baharat olarak, bitkisel çay yapımında, parfümeri ve kozmetik sanayinde kullanıldığı (Ortiz ve Fernandez, 1992) gibi halk ilacı olarak kramplar, kas ağrıları, mide bulantısı, hazımsızlık, ishal ve bulaşıcı hastalıklar gibi çeşitli rahatsızlıkları tedavi etmede kullanılmaktadır (Şahin ve ark., 2003). Satureja antioksidan, antimikrobiyal (Mohammed ve ark., 2019) ve antifungal (Bozhüyük ve ark., 2015) etkilere sahip olup gıdalarda bozulmayı engellemek amacı ile kullanılabileceği (Özkalp ve Özcan, 2009) bildirilmektedir. Dünyada olduğu gibi Türkiye' de ticareti yapılan tıbbi ve aromatik bitkilerin bir kısmı doğadan toplanarak temin edilirken bir kısmının da kültürü yapılmaktadır. Lamiaceae familyasına ait Satureja hortensis Anadolu'da farklı isimlerle bilinmekle birlikte (cibreska, kekik, anık, çibriska, çubriza, geyik otu) literatürlerde yaygın ismi sater olarak geçmekte ve halk arasında daha çok kekik olarak bilinmektedir. Tek yıllık olması nedeniyle tarla tarımı ekim sisteminde kolaylıkla yer alabilmektedir. Bunun yanında kısa vejetasyon süresine sahip olması ve hızlı gelişmesi nedeniyle bir yılda iki ürün alınabilmektedir.

Türkiye'de tarımsal üretimin düşük olmasının birçok nedeni vardır. Birim alan verim düşüklügünün önemli sebeplerinden birisi, tarım alanlarının büyük bir kısmının organik madde içeriğinin düşük olmasıdır (Eyüpoğlu, 1999). Bu nedenle özellikle kuru tarım arazilerinde, gübreleme ile birlikte modern tarım teknikleri kullanılsa dahi verim, belirli bir seviyenin üzerine çıkamamaktadır. Sulu tarım arazilerinde ise gübreleme ile birlikte verim artışları sağlansa da, organik madde eksikliğinin negatif yansıması olmaktadır. Toprakta organik madde oranını artırmak için ahır gübrelemesi, yeşil gübreleme, baklagillerin ekim nöbetine girmesi, kompost, vermikompost vb. uygulamalar yapılmaktadır (Tejada ve ark., 2008). Bitkisel üretimde verimi arttırmak için kullanılan yoğun pestisit ve gübreler önemli sağlık sorunlarına neden olabilmektedir. Ayrıca tarım topraklarının yapısında bozulmalara ve verimsizleşmesine sebep olmaktadır (Chen ve ark., 2010). İnsanların kimyasal kalıntılar nedeniyle tükettikleri ürünlerde doğalı tercih etmeleri organik veya iyi tarım üretimini arttırmış ve büyük bir pazar oluşturmuştur. Vermikompost (solucan gübresi), organik materyallerin solucanlar tarafindan humus benzeri materyallere dönüştürülmesi ile elde edilmektedir (Garg ve ark., 2010). Vermikompost, toprağa organik madde, bitki besin elementleri, hormonlar, enzimler, hümik maddeler kazandırmakta ve mikrobiyal aktiviteyi artırarak toprak verimliliğini ve canlılığını olumlu yönde etkilemektedir (Ceritoğlu, 2019). Tavalı ve ark. (2014) vermikompost uygulamasının toprağın organik madde içeriğini arttırdığını, Singh ve ark. (2008) ve Köksal ve ark. (2017) vermikompostun toprağın fiziksel, kimyasal ve biyolojik özelliklerinin iyileştirdiğini ve verime olumlu etki yaptığını bildirilmişlerdir. Bu araştırma, Satureja hortensis 'in herba verimi ve uçucu yağ oranına topraktan sıvı solucan gübresi uygulamasının etkisini araştırmak amacıyla yürütülmüştür. 


\section{MATERYAL VE YÖNTEM}

\section{Fide Yetiştirme}

Satureja hortensis tohumları Nisan ayının ilk haftasında sera koşullarında köklendirme ortamı olarak perlit ve torf (1:1) ile doldurulmuş viollere 2-3 adet ekilmiştir. Tohumlar ekimden itibaren otomatik sisleme şeklinde düzenli sulanmış ve çıkış yaptıktan sonra tekleme yapılmıştır. Fideler sera ortamında 30 gün büyümeye bırakılmış ve yaklaşı $10 \mathrm{~cm}$ boyuna ulaştıklarında araziye dikilmiştir.

\section{İklim ve Toprak Özellikleri}

Denemenin yürütüldüğü 2019 ve 2020 yıllarının vejetasyon döneminde (Mayıs-Eylül) ortalama sıcaklık sırasıyla, 20.1 ve $21.7^{\circ} \mathrm{C}$, toplam yağış miktarı sırasıyla, 108.2 ve $139.7 \mathrm{~mm}$ olmuştur (Çizelge 1).

Çizelge 1. Deneme yıllarının ve alanının bazı iklim verileri*

\begin{tabular}{|c|c|c|c|c|c|c|c|}
\hline \multirow[b]{2}{*}{ İklim verileri } & \multirow{2}{*}{ Yillar } & \multicolumn{5}{|c|}{ Aylar } & \multirow{2}{*}{$\begin{array}{l}\text { Toplam } \\
\text { veya Ort. }\end{array}$} \\
\hline & & $\overline{\text { Mayıs }}$ & Haziran & Temmuz & Ağustos & Eylül & \\
\hline Ortalama & 2019 & 17.0 & 20.6 & 23.4 & 24.4 & 18.9 & 20.1 \\
\hline \multirow[t]{3}{*}{ Sicaklık $\left({ }^{\circ} \mathrm{C}\right)$} & 2020 & 18.4 & 19.8 & 23.3 & 23.2 & 19.8 & 21.7 \\
\hline & Uzun yıllar & 15.6 & 20.2 & 23.6 & 25.8 & 18.3 & 20.7 \\
\hline & 2019 & 62.9 & 29.4 & 4.1 & 10.2 & 1.6 & 108.2 \\
\hline \multirow[t]{2}{*}{ Yağış (mm) } & 2020 & 56.6 & 34.2 & 16.1 & 14.1 & 18.7 & 139.7 \\
\hline & Uzun yillar & 51.4 & 29.8 & 14.6 & 0.3 & 15.4 & 111.5 \\
\hline
\end{tabular}

*Isparta meteoroloji istasyonu kayıtları

Deneme alanı toprağı her iki yılda da (2019 ve 2020) kumlu-tınlı bir yapıya sahip olup, hafif bazik (pH: 7.6 ve 7.8), kireç oranı yüksek (\%20.7 ve \%18.6) ve organik madde oranı (\%1.93 ve \%1.54) düşüktür (Çizelge 2). Uygulamaların hasat sonrası toprak yapısına etkisi her iki yılda da ekim öncesi değerlere yakın çıkmıştır (Çizelge 2).

Çizelge 2. Deneme alanı toprağının bazı özellikleri

\begin{tabular}{llllll}
\hline \multicolumn{5}{c}{ Ekim öncesi toprak özellikleri } \\
\hline Yıllar & Derinlik $(\mathbf{c m})$ & $\begin{array}{l}\mathbf{p H} \\
\mathbf{( \% )}\end{array}$ & $\begin{array}{l}\text { Kireç } \\
\mathbf{( \% )}\end{array}$ & $\begin{array}{l}\text { Organik madde } \\
\mathbf{( \% )}\end{array}$ & Bünye \\
\hline 2019 & $0-60$ & 7.6 & 20.7 & 1.93 & Kumlu tınlı \\
2020 & $0-60$ & 7.8 & 18.6 & 1.54 & \multirow{2}{*}{ Kumlu tınlı } \\
\hline \multicolumn{7}{c}{ Hasat sonrası toprak } & \\
\hline 2019 & $0-60$ & 7.4 & 20.1 & 1.86 & \\
2020 & $0-60$ & 7.7 & 19.2 & 1.66 & \\
\hline
\end{tabular}

\section{Fidelerin Araziye Şaşırtılması ve Denemenin Kurulması}

Deneme, Isparta Uygulamalı Bilimler Üniversitesi Araştırma ve Uygulama arazisinde her iki yılda da eşit koşullarda yürütülmesi amacıyla aralarında 100 metre olan ayrı alanlarda 2019 ve 2020 yıllarında tesadüf blokları deneme desenine göre 3 tekerrürlü olarak kurulmuştur. Araştırma; 1. Geleneksel üretim (kontrol), 2. Yalın sıvı solucan gübresi ve 3 . Geleneksel üretim + solucan gübresinin birlikte uygulanması olarak planlanmıştır.

Geleneksel üretim (Kontrol): Dekara saf olarak $10 \mathrm{~kg}$ azot çiçeklenme öncesi dönemde ve birinci hasat sonrasında olmak üzere ikiye bölünerek ve $5 \mathrm{~kg}$ fosfor dikimden önce toprağa DAP (diamonyum 
fosfat-18:46) formunda uygulanmıştır. Üst azot gübrelemesi amonyum sülfat $(\% 21 \mathrm{~N})$ formunda verilmiştir (Katar ve Aytaç, 2017).

Sıvı solucan gübresi: Dekara önerilen 1L solucan gübresi her parseldeki bitkilerin kök bölgesine sulama suyu ile birlikte üç defa toprağa uygulanmıştır. Birinci uygulama; dikimden 15 gün sonra, ikinci uygulama çiçeklenme başlangıcı ve üçüncü uygulama ise bitkinin gelişmesini hızlandırmak amacıyla ilk biçimden hemen sonra yapılmıştır.

Denemede kullanılan solucan gübresinin içeriği $\mathrm{pH} 7-9$, \%3.0 organik madde, \%2.20 toplam hümik+fluvik asit, \%0.5 toplam azot ve \%1 organik karbondan oluşmaktadır.

Satureja hortensis fideleri her iki yılda da Mayıs ayının ilk haftasında sıra arası $40 \mathrm{~cm}$ ve sıra üzeri $20 \mathrm{~cm}$ dikim sıklığında sıra uzunluğu $4 \mathrm{~m}$ ve her parsel 5 sıra olacak şekilde viyol toprağı ile birlikte dikim yapılmış ve can suyu verilmiştir. Fideler toprağa tutununcaya kadar iki sulama daha yapılmıştır. Tutmayan fidelerin yerine yeni fideler aşılanmıştır. Dikimden sonra deneme alanı düzenli olarak yabancı otlardan temizlenmiş ve damlama sulama şeklinde bitkinin ihtiyaç duyduğu zamanlarda sulama yapılmıştır

Satureja hortensis'in bitki boyu kök boğazı ile en uzun dalın ucu arasındaki mesafe cm olarak ölçülmüştür. Bitkilerin tam çiçeklenme döneminde toprak yüzeyinden $10 \mathrm{~cm}$ kadar yükseklikten 2-3 sürgün bırakılarak budama makası ile birinci hasatlar sirasıyla 04.08 .2019 ve 30.07.2020, ikinci hasatlar 16.10.2019 ve 13.10.2020 tarihlerinde yapılmıştır. Yaş herba ağırlıkları tartıldıktan sonra gölge ve havadar bir ortamda 10 gün raflarda kurumaya bırakılarak drog herba ağırlıkları belirlenmiştir. Kuruyan bitkilerin yaprakları saplarından elle sıyrıldıktan sonra drog yaprak ağırlıkları tartılmış ve dekara çevrilerek verimleri $\left(\mathrm{kg} \mathrm{da}^{-1}\right)$ hesaplanmıştır.

\section{Uçucu Yăg Oranı}

Hasat sonrasında yaş herba ve drog yaprak uçucu yağ oranı, Clevenger tipi hidro- distilasyon cihazında su distilasyonu yöntemiyle, yaş herba uçucu yağ oranı için 100 gr numune üzerine $750 \mathrm{ml}$, drog yaprak için 30 gr numune üzerine $250 \mathrm{ml}$ su eklenerek 2 saat süre ile distile edilmiştir. Distilasyon sonrasında ölçülü bölümde toplanan yağ miktarı ölçülerek \% uçucu yağ oranı hesaplanmıştır.

Tesadüf blokları deneme desenine göre kurulan çalışmada, Satureja hortensis bitkisinden iki biçim yapıldığı için uygulamalara ait biçim sayılarının karşılaştırmaları faktöriyel deneme desenine göre varyans analizleri Jump 5 istatistik paket programından faydalanılarak yapılmış, elde edilen ortalamalar Duncan testine göre karşılaştırılmıştır (Steel ve Torrie, 1980).

\section{BULGULAR ve TARTIȘMA}

Satureja hortensis bitkisinin toplam yaş ve drog herba verimi bakımından yıllar arasındaki farklar istatistiksel olarak önemli çıkarken, incelenen diğer özellikler arasında farklar önemsiz olmuştur (Çizelge 3). Satureja hortensis'in toplam yaş ve drog herba verimi ikinci yıl daha yüksek olmuştur. Bu farklılık; ikinci yılda yağış miktarı ve günlük sıcaklık ortalamasının daha yüksek olması nedeniyle bitkinin hızlı gelişmesi ve vejetatif aksamın artmasıyla açıklanabilir.

Çizelge 3. Satureja'nın incelenen özelliklerinin yıllara ait ortalamaları

\begin{tabular}{lllllll}
\hline Yıllar & $\begin{array}{l}\text { Toplam yaş } \\
\text { herba verimi } \\
\left(\mathrm{kg} \mathrm{da}^{-1}\right)\end{array}$ & $\begin{array}{l}\text { Toplam drog } \\
\text { herba verimi } \\
\left(\mathrm{kg} \mathrm{da}^{-1}\right)\end{array}$ & $\begin{array}{l}\text { Toplam drog } \\
\text { yaprak verimi } \\
\left(\mathrm{kg} \mathrm{da}^{-1}\right)\end{array}$ & $\begin{array}{l}\text { Bitki boyu } \\
(\mathrm{cm})\end{array}$ & $\begin{array}{l}\text { Yaş uçucu } \\
\text { yağ oranı } \\
(\%)\end{array}$ & $\begin{array}{l}\text { Drog } \\
\text { yaprak }\end{array}$ \\
\hline 2019 & $1249.3 \mathrm{~B}$ & $370.4 \mathrm{~B}$ & 182.1 & 38.4 & 0.53 & 3.03 \\
2020 & $1501.5 \mathrm{~A}$ & $497.6 \mathrm{~A}$ & 199.2 & 37.7 & 0.49 & 3.10 \\
F değeri $\mathrm{Y}_{11}$ & $26.45^{* *}$ & $121.4^{* *}$ & ö.d & ö.d & ö.d & ö.d \\
\hline
\end{tabular}

$* *$ : $\mathrm{P} \leq 0.01$ düzeyinde önemli, öd: önemli değil 
Satureja hortensis bitkisinin yaş herba uçucu yağ oranı hariç incelenen tüm özellillerin birinci ve ikinci biçim ortalamaları arasındaki farklar istatistiksel olarak önemli çıkmış ve birinci biçim ortalamaları daha yüksek olmuştur. Satureja hortensis' in bitki boyu, yaş herba, drog herba, drog yaprak verimi ve drog yaprak uçucu yağ oranı birinci biçimde sırasıyla, $41.7 \mathrm{~cm}, 765.2 \mathrm{~kg} / \mathrm{da}, 240.3 \mathrm{~kg} / \mathrm{da}$, $125.7 \mathrm{~kg} / \mathrm{da}$ ve $\% 3.73$, ikinci biçimde $35.1 \mathrm{~cm}, 483.5 \mathrm{~kg} / \mathrm{da}, 130.1 \mathrm{~kg} / \mathrm{da}, 56.2 \mathrm{~kg} / \mathrm{da}$ ve $\% 2.34$ olurken, bu özellikler ikinci yıl birinci biçimde $40.9 \mathrm{~cm}, 954.1 \mathrm{~kg} / \mathrm{da}, 320.1 \mathrm{~kg} / \mathrm{da}, 140.1 \mathrm{~kg} / \mathrm{da}$ ve \%3.83, ikinci biçimde $34.6 \mathrm{~cm}, 547.3 \mathrm{~kg} / \mathrm{da}, 177.5 \mathrm{~kg} / \mathrm{da}$ ve $59.2 \mathrm{~kg} / \mathrm{da}$ ve $\% 2.37$ olarak belirlenmiştir (Çizelge 4, 5). Satureja hortensis bitkisinde birinci hasattan sonra bitkide odunlaşma daha fazla ve yaprak oranı daha az olduğu gözlemlenmiştir. Bu durum ikinci hasatta verimin düşük olmasına neden olmuştur. Bunun yanında birinci hasatta verimin yüksek olması; bitkinin vejetasyon süresinin daha uzun ve gelişme sıcaklığının daha uygun olmasından dolayı hızlı gelişmesi ve birinci hasattan sonra bitkinin yavaş gelişmesi, dallanmanın daha az ve sürgünlerin daha kısa kalması ile açıklanabilir. Shams ve ark. (2012) kekik türlerinde bitkide sürgün sayısı ve kanopi çapının drog herba verimini önemli oranda etkilediğini bildirmişlerdir. Héjja ve ark. (2002), Dzida ve ark. (2015) ve Katar ve ark. (2017) Satureja hortensis bitkisinin birinci biçiminde yaş herba ve drog yaprak veriminin ikinci biçimden daha yüksek olduğunu bildirmişlerdir.

Gübre uygulamalarının Satureja hortensis bitkisinin yaş herba uçucu yağ oranı hariç, bitki boyu, yaş herba verimi, drog herba verimi, drog yaprak verimine ve drog yaprak oranına etkisi her iki y1lda istatistiksel olarak önemli olmuştur. Satureja hortensis' in en yüksek yaş herba verimi, drog herba verimi, drog yaprak verimi, yaş herba uçucu yağ oranı ve drog yaprak uçucu yağ oranı birinci yıl birinci biçimde $1142.2 \mathrm{~kg} \mathrm{da}^{-1}, 340.7 \mathrm{~kg} \mathrm{da}^{-1}, 183.7 \mathrm{~kg} \mathrm{da}^{-1}, \% 0.55 \mathrm{ve} \% 4.13$, ikinci biçimde $707.3 \mathrm{~kg} \mathrm{da}^{-1}, 176,5 \mathrm{~kg} \mathrm{da}^{-}$ $1,80.5 \mathrm{~kg} \mathrm{da}^{-1}, \% 0.52$ ve $\% 2.53$ olarak belirlenmiştir. Bu özellikler ikinci y1l birinci biçimde $1250.5 \mathrm{~kg}$ $\mathrm{da}^{-1}, 375.0 \mathrm{~kg} \mathrm{da}^{-1}, 170.0 \mathrm{~kg} \mathrm{da}^{-1}, \% 0.56$ ve $\% 4.26$ ve ikinci biçimde $611.2 \mathrm{~kg} \mathrm{da}^{-1}, 207.7 \mathrm{~kg} \mathrm{da}^{-1}$ ve 76.3 $\mathrm{kg} \mathrm{da}^{-1}, \% 0.49$ ve \%2.59 ile G.Ü+S.G uygulamasından elde edilmiştir (Çizelge 4,5). İncelenen özelliklerin en düşük değerleri ise solucan gübresinin yalın uygulamasında belirlenmiştir. Geleneksel üretim+solucan gübresinin birlikte uygulamasından elde edilen drog toplam yaprak verimi yalın solucan gübresine göre birinci y1l \%62.8, ikinci y1l \%35.7 ve geleneksel üretimden ise birinci y11 \%30.4, ikinci yıl \%21.5 oranında daha fazla olmuştur (Çizelge 3). Yalın olarak uygulanan solucan gübresinin azot içeriğinin düşük $(\% 0.5)$ olması, satureja bitkisinin kısa boylu ve yaprak oranının azalmasına neden olmuş (Çizelge 5), bu durum herba verimine negatif olarak yansımıştır. Azot bitkilerde vejetatif aksamın gelişmesini teşvik etmektedir, yetersizliğinde yaprak, sap ve gövde organları zayıf gelişmektedir (Kacar, 2013). En yüksek verimin tespit edildiği G.Ü+S.G uygulamasında, kimyasal azotlu gübrelemeye solucan gübresinin azot miktarı ek katkı yapmış ve bitkinin vejetatif organlarının gelişmesini ve dolayısıyla herba verimini artırmıştır. Araştırmada, birinci biçim uçucu yağ oranları ikinci biçimden daha yüksek olmuştur. Bu farklılık birinci biçimde bitkinin vejetasyon süresinin daha uzun, yaprak/sap oranının yüksek ve sıcaklığın uygun olmasından kaynaklanmaktadır. Uygulamalar; satureja bitkisinin yaş herba uçucu yağ oranını etkilemezken, drog yaprak uçucu yağ oranı G.Ü+S.G'nin birlikte uygulamasında daha yüksek olmuştur. Tıbbi ve aromatik bitkilerde uçucu yağlar doku, organ ve gelişme kısımlarında spesifik biyosentetik enzimler tarafından sentezlenmekte ve iklim faktörleri, gübreleme, sulama, hasat zamanı ve kurutma şekli gibi bir çok faktörün etkisi altındadır (Alaca ve Arslan, 2012). Aşçı (2009) yeşil herba verimi 790.5-1085.0 $\mathrm{kg} \mathrm{da}^{-1}$, drog herba verimi 345.4- 455.7 $\mathrm{kg} \mathrm{da}^{-1}$, drog yaprak verimi için 76.3-101.2 $\mathrm{kg} \mathrm{da}^{-1}$ ve uçucu yağ oranının \%3.15-2.30, Katar ve ark. (2011) yaş herba verimi 216.6-297.0 kg da-1, drog yaprak veriminin 45.3-66.0 kg da $\mathrm{kg}^{-1}$, yaş yaprak uçucu yağ oranının \%1.66-2.20 ve Çoban (2019) toplam yaş herba verimi $5745.0-1077.5 \mathrm{~kg} \mathrm{da}^{-1}$, toplam drog herba verimi $1624.5-599.5 \mathrm{~kg} \mathrm{da}^{-1}$ ve uçucu yağ oranı \%2.76-3.58 arasında değiştiğini bildirmişlerdir. 
Çizelge 4. Satureja hortensis'in yaş herba, drog herba ve drog yaprak verimleri

\begin{tabular}{|c|c|c|c|c|c|c|c|c|c|c|}
\hline \multirow[b]{2}{*}{ Yillar } & \multirow{2}{*}{$\begin{array}{l}\text { Gübre uyg./ } \\
\text { Biçim zam. }\end{array}$} & \multicolumn{3}{|c|}{ Yaş herba verimi $\left(\mathrm{kg} \mathrm{da}^{-1}\right)$} & \multicolumn{3}{|c|}{ Drog herba verimi $\left(\mathrm{kg} \mathrm{da}^{-1}\right)$} & \multicolumn{3}{|c|}{ Drog yaprak verimi $\left(\mathrm{kg} \mathrm{da}^{-1}\right)$} \\
\hline & & 1. Biçim & 2. Biçim & Toplam & 1. Biçim & 2. Biçim & Toplam & 1. Biçim & 2. Biçim & Toplam \\
\hline \multirow{4}{*}{2019} & G.Ü & $928.7 \mathrm{~b}$ & $532.6 \mathrm{~b}$ & $1461.3 \mathrm{~b}$ & $240.1 \mathrm{~b}$ & $109.4 \mathrm{~b}$ & $349.5 \mathrm{~b}$ & $129.8 \mathrm{~b}$ & $54.1 \mathrm{~b}$ & $183.9 \mathrm{~b}$ \\
\hline & S.G & $425.0 \mathrm{c}$ & $312.1 \mathrm{c}$ & $737.1 \mathrm{c}$ & $140.0 \mathrm{c}$ & $104.1 \mathrm{~b}$ & $244.1 \mathrm{c}$ & $63.9 \mathrm{c}$ & $34.4 \mathrm{c}$ & $98.3 \mathrm{c}$ \\
\hline & G. Ü+S.G & $942.2 \mathrm{a}$ & $607.3 \mathrm{a}$ & $1549.5 \mathrm{a}$ & $340.7 \mathrm{a}$ & $176.5 \mathrm{a}$ & $517.2 \mathrm{a}$ & $183.7 \mathrm{a}$ & $80.5 \mathrm{a}$ & $264.2 \mathrm{a}$ \\
\hline & F değeri & $35.16^{* *}$ & $19.87^{* *}$ & $29.78 * *$ & $135.9^{* *}$ & $112.1^{* *}$ & $123.70 * *$ & $203.3^{* *}$ & $119.42 * *$ & $214.3^{* *}$ \\
\hline \multicolumn{2}{|c|}{ Biçim zamanı ortalama } & $765.2 \mathrm{~A}^{* *}$ & $483.5 \mathrm{~B}$ & & $240.3 \mathrm{~A}^{* *}$ & $130.1 \mathrm{~B}$ & & $125.7 \mathrm{~A}^{* *}$ & $56.2 \mathrm{~B}$ & \\
\hline & C.V (\%) & 5.47 & 3.14 & 2.10 & 4.58 & 3.98 & 2.47 & 3.81 & 4.09 & 2.87 \\
\hline \multirow{4}{*}{2020} & G.Ü & $982.3 \mathrm{~b}$ & $549.9 \mathrm{~b}$ & $1532.2 \mathrm{~b}$ & $317.2 \mathrm{~b}$ & $174.1 \mathrm{~b}$ & $491.3 \mathrm{~b}$ & $135.9 \mathrm{~b}$ & $57.3 \mathrm{~b}$ & $193.2 \mathrm{~b}$ \\
\hline & S.G & $831.5 \mathrm{c}$ & $481.1 \mathrm{c}$ & $1312.6 \mathrm{c}$ & $268.1 \mathrm{c}$ & $150.7 \mathrm{~b}$ & $418.8 \mathrm{c}$ & $114.4 \mathrm{c}$ & $43.8 \mathrm{c}$ & $158.2 \mathrm{c}$ \\
\hline & G.Ü+S.G & $1050.5 \mathrm{a}$ & $611.2 \mathrm{a}$ & $1661.7 \mathrm{a}$ & $375.0 \mathrm{a}$ & $207.7 \mathrm{a}$ & $582.7 \mathrm{a}$ & $170.0 \mathrm{a}$ & $76.3 \mathrm{a}$ & $246.3 \mathrm{a}$ \\
\hline & $\mathrm{F}$ değeri & $82.46^{* *}$ & $66.58 * *$ & $104.10^{* *}$ & $7.12 * *$ & $9.17 * *$ & $69.8 * *$ & $12.72^{* *}$ & $18.9^{* *}$ & $66.89 * *$ \\
\hline \multicolumn{2}{|c|}{ Biçim zamanı ortalama } & $954.1 \mathrm{~A}^{* *}$ & $547.3 \mathrm{~B}$ & & $320.1 \mathrm{~A}^{* *}$ & $177.5 \mathrm{~B}$ & & $140.1 \mathrm{~A}^{* *}$ & $59.2 \mathrm{~B}$ & \\
\hline & C.V (\%) & 2.41 & 2.54 & 3.78 & 3.61 & 5.14 & 3.25 & 2.98 & 2.47 & 5.41 \\
\hline
\end{tabular}

G.Ü: Geleneksel üretim, S.G: Solucan gübresi, **: $\mathrm{P} \leq 0.01$ düzeyinde önemli

Aynı sütunda benzer harfler ile gösterilen ortalamalar arasında istatistiksel olarak fark yoktur

Çizelge 5. Satureja hortensis'in bitki boyu, yaş herba ve ve drog herba uçucu yağ oranları

\begin{tabular}{|c|c|c|c|c|c|c|c|}
\hline \multirow[b]{2}{*}{ Yillar } & \multirow{2}{*}{$\begin{array}{l}\text { Gübre uyg./ } \\
\text { Biçim zam. }\end{array}$} & \multicolumn{2}{|c|}{ Bitki boyu (cm) } & \multicolumn{2}{|c|}{ Yaş herba U.Y.O (\%) } & \multicolumn{2}{|c|}{ Drog yaprak U.Y.O (\%) } \\
\hline & & 1. Biçim & 2. Biçim & 1. Biçim & 2. Biçim & 1. Biçim & 2. Biçim \\
\hline \multirow{6}{*}{2019} & G.Ü & $43.2 \mathrm{~b}$ & $37.2 \mathrm{~b}$ & 0.55 & 0.53 & $3.73 \mathrm{~b}$ & $2.20 \mathrm{~b}$ \\
\hline & S.G & $35.8 \mathrm{c}$ & $29.7 \mathrm{c}$ & 0.51 & 0.52 & $3.33 \mathrm{~b}$ & $2.26 \mathrm{~b}$ \\
\hline & G.Ü+S.G & $46.2 \mathrm{a}$ & $38.4 \mathrm{a}$ & 0.58 & 0.56 & $4.13 \mathrm{a}$ & $2.53 \mathrm{a}$ \\
\hline & F değeri & $26.45^{* *}$ & $5.88 *$ & $1.34^{\ddot{d}}$ & 2.19 öd & $6.08 *$ & $4.08 * *$ \\
\hline & Biçim zamanı ortalama & $41.7 \mathrm{~A}^{* *}$ & $35.1 \mathrm{~B}$ & $0.55^{\text {öd }}$ & 0.53 & $3.73 \mathrm{~A}^{* *}$ & $2.34 \mathrm{~B}$ \\
\hline & C.V (\%) & 2.47 & 3.30 & 4.40 & 3.25 & 3.21 & 2.25 \\
\hline \multirow{4}{*}{2020} & G.Ü & $41.5 \mathrm{~b}$ & $34.2 \mathrm{~b}$ & 0.54 & 0.47 & $3.40 \mathrm{c}$ & $2.53 \mathrm{a}$ \\
\hline & S.G & $37.6 \mathrm{c}$ & $32.5 \mathrm{~b}$ & 0.51 & 0.48 & $3.83 \mathrm{~b}$ & $1.98 \mathrm{~b}$ \\
\hline & G. Ü+S.G & $43.6 \mathrm{a}$ & $37.3 \mathrm{a}$ & 0.56 & 0.49 & $4.26 \mathrm{a}$ & $2.59 \mathrm{a}$ \\
\hline & F değeri & $15.60 * *$ & $3420^{* *}$ & $1.36^{\text {öd }}$ & $1.49^{\text {öd }}$ & $6.40 *$ & $76.56 * *$ \\
\hline \multicolumn{2}{|r|}{ Biçim zamanı ortalama } & $40.9 \mathrm{~A}^{* *}$ & $34.6 \mathrm{~B}$ & $0.54 \mathrm{~A}^{* *}$ & $0.48 \mathrm{~B}$ & $3.83 \mathrm{~A}^{* *}$ & $2.37 \mathrm{~B}$ \\
\hline \multicolumn{2}{|r|}{ C.V (\%) } & 3.14 & 1.25 & 1.47 & 2.54 & 3.74 & 3.65 \\
\hline
\end{tabular}

G.Ü: Geleneksel üretim, S.G: Solucan gübresi, **: $\mathrm{P} \leq 0.01$ düzeyinde önemli, öd: önemli değil

Aynı sütunda benzer harfler ile gösterilen ortalamalar arasında istatistiksel olarak fark yoktur.

\section{SONUÇ}

Yalın sıvı solucan gübrelemesinde elde edilen Satureja hortensis'in bitki boyu, yaş herba ve drog herba verimi ile uçucu yağ oranı değerleri, geleneksel üretim ve G.Ü+S.G'nin birlikte uygulanmasına göre daha düşük olmuştur. İncelenen karakterlerin en yüksek değerleri geleneksel üretim+solucan gübresinin birlikte uygulanmasında belirlenmiştir. $\mathrm{Bu}$ sonuç solucan gübresinin ek olarak uygulanmasının verime önemli oranda katkısının olduğunu göstermektedir. Birinci biçimlerde elde edilen ortalama verim değerleri ikinci biçimden önemli ölçüde daha yüksek olmuştur. Tipik bir karasal iklim özelliği gösteren Isparta ve benzeri koşullarda Satureja hortensis bitkisinde birinci hasattan sonra normal bakım işlemleri yapılarak ikinci biçim elde edilebilir.

Satureja bitkisinde kimyasal gübrelemeye ek olarak uygulanan vermikompostun yalın solucan gübresine göre \%35.7-62.8 ve geleneksel üretime göre ise \%21.5-30.4 oranında daha yüksek drog herba verimi elde edilmesi dikkate alındığında vermikompost uygulamasının ekonomik olduğu düşünülmektedir.

Sonuç olarak, daha yüksek yaş herba ve drog yaprak veriminden dolayı solucan gübresinin geleneksel üretim ile birlikte uygulanması önerilmektedir. 


\section{Çıkar Çatıșması}

Çalışmada kullanılan solucan gübresi bir zirai ilaç bayisinden temin edilmiştir. Ticari olarak satılan bir gübre olup, üretici firma ile "istihdam, ortaklık, danışmanlıklar, hisse senedi sahipliği, hizmet karşılığı ödenen ücretler, ücretli bilirkişilik, akrabalık veya yakın kişisel ilişkiler" ve benzeri herhangi bir çıkar ilişkisi yoktur.

\section{Yazar Katkısı}

Makalenin planlanması, yürütülmesi ve yazılması makale tek yazarı olarak tarafımca yapıldığı beyan ederim.

\section{KAYNAKLAR}

Acıbuca V, Budak DB, 2018. Dünya'da ve Türkiye'de tıbbi ve aromatik bitkilerin yeri ve önemi. Çukurova Tarım G1da Bilimleri Dergisi, 33(1): 37-44.

Alaca F, Arslan N, 2012. Sekonder metabolitlerin bitkiler açısından önemi. Ziraat Mühendisliği, 358: 48-55.

Aşçı M, 2009. Çukurova Koşullarında Satureja hortensis L.'nin Çiçeklenme Döneminde Tarımsal Karakterler ve Uçucu Yağ Oranındaki Değişimlerin Araştırılması. Çukurova Üniversitesi Fen Bilimleri Enstitüsü, Yüksek Lisans Tezi (Basılmış).

Bozhüyük AU, Kordali Ş, Bölük G, 2015. Satureja hortensis L. uçucu yağının antifungal etkisi. Atatürk Üniversitesi Ziraat Fakültesi Dergisi, 46(2): 107-112.

Ceritoğlu M, Şahin S, Erman M, 2019. Vermikompost üretim tekniği ve üretimde kullanılan materyaller. Türkiye Tarımsal Araştırmalar Dergisi, 6(2): 230-236.

Chen G, Zheng Z, Yang S, Fang C, Zou X, Luo Y, 2010. Experimental co-digestion of corn stalk and vermicompost to improve biogas production. Waste Management, 30(10): 1834-1840.

Çoban ZD, 2019. Farklı Lokasyon ve Sıra Arası Mesafelerinin Sater (Satureja hortensis L.) Bitkisinin Verim ve Kalite Özelliklerine Etkileri. Tekirdağ Namık Kemal Üniversitesi Fen Bilimleri Enstitüsü Yüksek Lisans Tezi (Basılmış).

Dzida K, Zawiślak G, Wierdak RN, Michałojć Z, Jarosz Z, Pitura K, Karczmarz K, 2015. Yield and quality of the summer savory herb (Satureia hortensis L.) grown for a bunch. Acta Scienterum Polonorum Hortorum Cultus, 14(3): 141-156.

Eyüpoğlu F, 1999. Türkiye Topraklarının Verimlilik Durumu. Köy Hizmetleri Genel Müdürlügü̈-Toprak ve Gübre Araştırma Enstitüsü Yayınları. Genel Yayın No: 220 Ankara- Türkiye.

Garg VK, Gupta R, Yadav A, 2010. Vermicomposting Technology for Solid Waste Management. http://www.environmentalexpert.com/Files/0/articles/9047/Vermicomposting_article_for_the_biofertilize r_people.pdf (Erişim Tarihi: 05.02.2021).

Hejja M, Bernaht J, Szentgyörgyı E, 2002. Comporative investigation of Satureja hortensis of different orijin. Proc. Int. Conf. On MAP. (eds: J. Bernáth et al), Acta Horticulture, 576: 65-68.

Kacar B, 2013. Temel Gübre Bilgisi. Nobel Yayıncılık No:695, Fen Bilimleri No: 063, Ankara-Türkiye.

Katar D, Arslan Y, Subaşı İ, Bülbül A, 2011. Ankara ekolojik koşullarında sater (Satureja hortensis L) bitkisinde uçucu yağ ve bileşenlerinin ontogenetik varyabilitesinin belirlenmesi. Tekirdağ Ziraat Fakültesi Dergisi, 8(2): 29-35.

Katar D, Kacar O, Kara N, Aytaç Z, Göksu E, Kara S, Katar N, Erbaş S, Telci İ, Elmastaş M, 2017. Ecological variation of yield and aroma components of summer savory (Satureja hortensis L.). Journal of Applied Research on Medicinal and Aromatic Plants, 7: 131-135.

Katar N, Aytaç Z, 2017. Farklı Azot Dozlarının Sater (Satureja hortensis L.) Bitkisinde Verim ve Kalite Özellikleri Üzerine Etkisi, 12. Tarla Bitkileri Kongresi, 12-15 Ekim 2017, Kahramanmaraş.

Katar N, Aytaç Z, 2019. Sater (Satureja hortensis L.) genotiplerinin farklı lokasyonlarda agronomik ve kalite özelliklerinin belirlenmesi. Ziraat Fakültesi Dergisi, 14 (2): 253-269.

Köksal SB, Aksu G, Altay H, 2017. Vermikompostun bazı toprak özellikleri ve pazı bitkisinde verim üzerine etkisi. Çanakkale Onsekiz Mart Üniversitesi Ziraat Fakültesi Dergisi, 5(2): 123-128 
Mohammed FS, Dastan T, Sevindik M, Selamoğlu Z, 2019. Antioxidant, antimicrobial activity and therapeutic profile of Satureja hortensis from Erzincan province. Cumhuriyet Tip Dergisi, 41 (3): 558-562.

Ortiz PL, Fernandez I, 1992. Microscopic Study of Honey and Apiary Pollen from the Province of Sevile. Departmento de Biologia Vegetaly, Ecologia Facultad de Biologia, Apdo. 1095, 41080 Seville, Spain.

Özkalp B, Özcan M, 2009. Antibacterial activity of several concentrations of sater (Satureja hortensis L.) essential oil on spoilage and pathogenic food-related microorganisms. World Applied Sciences Journal, 6(4): 509514.

Sat1l F, Dirmenci T, Tümen G, Turan Y, 2008. Commercial and ethnic uses of Satureja (Sivri Kekik) species in Turkey. Ekoloji, 17: 1-7.

Shams A, Shakouri MJ, Kapourchal SA, Aslanpour M, 2012. Effect of nitrogen and phosphorus fertilizers on yield of Thymus daenensis in dry condition. Indian Journal of Science and Technology, 5: 1916-1920.

Singh R, Sharma RR, Kumar S, Gupta RK, Patil RT, 2008. Vermicompost substitution influences growth, physiological disorders, fruit yield and quality of strawberry (Fragaria $x$ ananassa Duch). Bioresource Technology, 99: 8507-8511.

Steel, RGD., Torrie JH, 1980. Principles and Procedures of Statistics. McGraw-Hill Book Company, Inc., New York, USA.

Şahin F, Karaman İ, Güllüce M, Öğütçü H, Şengül M, Adıgüzel A, Öztürk S, Kotan R, 2003. Evaluation of antimicrobial activities of Satureja hortensis L. Journal of Ethnopharmacology, 87: 61-65.

Tavalı İE, Uz İ, Orman Ş, 2014. Vermikompost ve tavuk gübresinin yazlık kabağın (Cucurbita pepo L. cv. Sakız) verim ve kalitesi ile toprağın bazı kimyasal özellikleri üzerine etkileri. Akdeniz Üniversitesi Ziraat Fakültesi Dergisi 27(2): 119-12.

Tejada M, Gonzalez JL, Garcia-Martinez AM, Parrado J, 2008. Effects of different green manures on soil biological properties and maize yield. Bio Resource Technology, 99:1758-1767. 